Jurnal Teknologi Informasi dan Ilmu Komputer (JTIIK)

Vol. 2, No. 1, April 2015, hlm. 67-72

\title{
SEGMENTASI KENDARAAN MENGGUNAKAN IMPROVE BLOB ANALYSIS (BA) PADA VIDEO LALU LINTAS
}

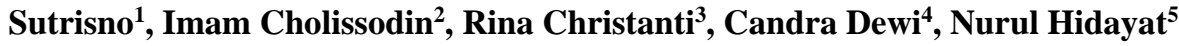 \\ ${ }^{12345}$ Program Studi Informatika dan Ilmu Komputer, Universitas Brawijaya \\ Email: ${ }^{1}$ trisno@ub.ac.id, ${ }^{2}$ imamcs@ub.ac.id, ${ }^{3}$ rnnyun@gmail.ac.id, ${ }^{4}$ dewi_candra@ub.ac.id, ${ }^{5}$ ntayadih@ub.ac.id
}

(Naskah masuk: 29 Januari 2015, diterima untuk diterbitkan: 17 Februari 2015)

\begin{abstract}
Abstrak
Penggunaan citra digital untuk keperluan penelitian sudah banyak dilakukan, salah satunya yaitu segmentasi. Segmentasi berfungsi untuk mendeteksi objek - objek yang terdapat pada citra, sehingga hasil segmentasi sangat penting untuk proses selanjutnya. Pada penelitian ini diusulkan teknik optimasi hasil background subtraction menggunakan kombinasi frame difference (FD) atau difference image dengan filter SDGD dan running average (RA) atau background updating dengan filter SDGD untuk diterapkan pada blob analysis. Alasan utama menggunakan penggabungan kedua metode tersebut adalah karena seringnya terdapat piksel objek yang tidak mampu dideteksi sehingga akan mengurangi tingkat optimasi pengenalan objek. Hasil pengujian akurasi dari 10 data uji yang masing - masing terdiri dari 30 frame menunjukkan bahwa aplikasi ini memiliki nilai akurasi tertinggi yakni $90 \%$ untuk pengujian threshold dan $100 \%$ untuk pengujian ukuran structure element. Sehingga dapat disimpulkan bahwa aplikasi ini mampu melakukan segmentasi kendaraan dengan baik.
\end{abstract}

Kata kunci: filter SDGD, blob analysis, video lalu lintas, background subtraction.

\begin{abstract}
The use of digital images for the purposes of research has been often applied, one of them is segmentation. Segmentation is used to detect objects contained in the image, so the segmentation result is very important for further processing. In this study, the results of the optimization technique proposed background subtraction using a combination of frame difference (FD) or a difference image with filter SDGD and running average (RA) or background updating with SDGD filter to be applied blob analysis. The main reason to use the merger of these two methods is that often there are pixels that are not able to detect objects that will reduce the level of optimization object recognition. The results of accuracy testing using 10 data testing for each data consisting of 30 frames shows that the system proposed in this paper has best accuracy of $90 \%$ for testing the threshold and 100\% for testing the size of structure element. So it can be concluded that this system capable to segmentation the vehicle properly.
\end{abstract}

Keywords: filter SDGD, blob analysis, traffic video, background subtraction

\section{PENDAHULUAN}

Indonesia merupakan negara yang memiliki banyak kota besar. Akan tetapi, dari sekian banyak kota tersebut ternyata sering mengalami permasalahan dalam bidang transportasi. Salah satu permasalahan tersebut adalah kemacetan. Kemacetan merupakan problem utama dalam transportasi. Meskipun telah setiap ruas jalan telah dilengkapi dengan alat pengatur lalu lintas yang lengkap, namun alat tersebut hanya mampu untuk mengatur berhenti dan berjalannya kendaraan tanpa adanya dukungan teknologi yang mampu untuk mengestimasi tingkat kepadatan kendaraan disetiap ruas jalan untuk membuat waktu berhenti dan berjalannya secara adaptif. Selain itu, bertambahnya jumlah kendaraan roda dua maupun roda empat juga merupakan faktor utama dalam kemacetan lalu lintas. Hal ini memang dipicu pula dengan sedikitnya rencana pembangunan jalan raya disetiap daerah di Indonesia, sehingga membuat tidak seimbang antara kapasitas jalan raya dengan jumlah kendaraan yang ada. Dan tentunya, permasalahan transportasi ini pada beberapa tahun mendatang dapat dipastikan akan semakin komplek jika tidak segera diatasi sedini mungkin.

Efek secara tidak langsung dari kemacetan ini adalah terkait dengan penurunan produktifitas dari setiap pengguna jalan raya. Karena waktu mereka akan habis diperjalanan untuk setiap hari - harinya. Kemudian terkait dengan polusi udara di jalan raya pun akan semakin meningkat dan tidak baik bagi kesehatan serta pada lingkungan. Atau bahkan akan menimbulkan pelanggaran lalu lintas dengan menentang arus untuk cepat sampai di tempat tujuan tanpa memperdulikan marka jalan, misalnya melewati trotoar dan menentang arus jalan, yang tanpa disadari oleh pengendara kadang menimbulkan kecelakaan atau membahayakan pengendara lain maupun pejalan kaki. Jika dianalisis dari beberapa kejadian di lalu lintas, maka dapat dikatakan bahwa perbandingan sebenarnya waktu tempuh normal dengan waktu tempuh karena adanya kemacetan bisa mencapai 2 sampai 3 kali lipat. Hal inilah yang 
kadang - kadang membuat seseorang terlambat sampai di tempat kerja, terlambat mengantarkan pesanan, sampai pada terlambat untuk mengikuti ujian dan lain sebagainya. Fakta - fakta di atas merupakan beberapa permasalahan utama dalam transportasi yang harus segera ditangani dengan serius. Oleh karena itu perlu dibuat suatu sistem yang mampu bekerja secara otomatis dan dapat membantu dalam mengatasi permasalahan - permasalahan tersebut. Sistem tersebut akan dilengkapi dengan kecerdasan buatan dari mesin pembelajaran yang dapat melatih secara mandiri dari setiap kejadian kejadian yang menjadi data masukan dan mampu memproses, sehingga mendapatkan keputusan yang optimal.

Pada penelitian sebelumnya yang dilakukan oleh Thou-Ho (2007), telah dicoba dibuat sistem penghitungan jumlah kendaraan mobil dan sepeda pada jalan raya menggunakan blob analysis. Dari hasil uji coba yang dilakukan didapatkan hasil ratarata akurasi sebesar $91.7 \%$ pada dua kondisi lalu lintas kendaraan, yaitu flowl (bi-directional/dua arah), flow2 dan flow3 (uni-directional/satu arah). Blob analysis tersebut didapatkan dari proses learning citra sequence yang diambil dari data input video dalam frame tertentu. Proses learning yang dilakukan pertama kali adalah dengan malakukan segmentasi objek bergerak, dalam hal ini adalah kendaraan, yang didasarkan pada background subtraction dari penghitungan selisih current frame dengan background awal. Background awal ini nantinya akan terus menerus di-update secara realtime menggunakan model updating dengan faktor pembobot terhadap current frame. Namun faktor pembobot tersebut harus di-set secara manual, dan tidak bersifat adaptif. Kemudian, pada proses tracking objek menggunakan fungsi match yang digunakan untuk menandai bahwa objek sedang bergerak adalah objek bergerak sebelumnya, sehingga sistem akan tetap mengenali objek - objek tersebut secara unik (Thou-Ho dkk. 2007).

Penelitian tentang adaptive background subtraction yang telah dilakukan Ruolin Zhang dan Jian Ding (2012), dicoba untuk mendapatkan nilai threshold yang adaptif untuk hasil citra subtraction dari citra di current frame dengan citra background. Namun nilai threshold tersebut juga masih menggunakan cara trial-and-error beberapa kali percobaan. Mereka mengatakan bahwa nilai threshold harus disesuaikan dengan lingkungan yang ada pada sekitar objek untuk menjamin hasil background subtraction yang optimal. Farah Yasmin Abdul Rahman dkk (2013) mengembangkan model background subtraction (BGS) menggunakan Second Derivative in Gradient Direction Filter (SDGD). Model tersebut dibuat dengan teknik integrasi dengan filter gradient-based edge detector. Filter SDGD tersebut digunakan untuk memperbaiki hasil BGS yang masih belum sempurna yang dilakukan dengan empat teknik yang sebelumnya sudah ada, yaitu frame difference (FD), approximate median (AM), running average (RA), dan running Gaussian average (RGA). Hal yang mendasari pengembangan filter tersebut adalah karena terdapat intensitas warna dari objek yang lebih kecil dibandingan dengan nilai threshold dan ukuran blob hasil tracking-nya terlalu kecil dan kurang sesuai dengan ukuran sebenarnya dari objek bergerak. Selain itu, filter SDGD juga digunakan untuk memperbaiki hasil deteksi tepi dari teknik dasar BGS yang ada sebelumnya terhadap piksel - piksel yang hilang. Dari hasil pengujian, terbukti bahwa kombinasi antara FD dengan filter SDGD meberikan hasil pre-proses terbaik pada algoritma jaringan syaraf tiruan (JST) untuk digunakan dalam membedakan antara objek manusia dan bukan manusia dengan akurasi terbaik sebesar 98.75\% (Rahman, F. Y. A. dkk. 2013).

Pada penelitian ini diusulkan teknik optimasi hasil background subtraction menggunakan kombinasi frame difference (FD) atau difference image (pada paper sebelumnya oleh Thou-Ho, 2007) dengan filter SDGD dan running average (RA) atau background updating (pada paper sebelumnya oleh Thou-Ho, 2007) dengan filter SDGD untuk diterapkan blob analysis. Alasan utama menggunakan penggabungan kedua metode tersebut adalah karena seringnya terdapat piksel objek yang tidak mampu dideteksi sehingga akan mengurangi tingkat optimasi pengenalan objek. Diharapkan dengan menggunakan teknik tersebut akan diperoleh hasil uji coba yang optimal.

\section{TINJAUAN PUSTAKA}

\subsection{Second Derivative In Gradient Direction (SDGD) Filter}

Dalam studi pengolahan citra, peneliti menggunakan derivatif pertama dan kedua untuk mendeteksi tepi objek berdasarkan gradien nya. Dengan menggunakan turunan pertama, lokasi tepi didefinisikan pada posisi maksimum yang curam dan menurun (descent) (Young, I. J. dkk. 2007). Metode deteksi tepi tradisional, seperti Prewitt, Sobel, dan Roberts, mengkonvolusi gambar dengan kernel tertentu (Young, I. J. dkk. 2007, Narendra, V. G. dkk. 2009). Namun, teknik ini menjadi sensitif terhadap noise dan kurang akurat (Narendra, V. G. dkk. 2009). Pada tahun 1986, detektor tepi Canny diperkenalkan, yang mewakili perbaikan atas metode tradisional (Narendra, V. G. dkk. 2009, Persoon, M. P. dkk. 2003). Detektor menerapkan smoothing Gaussian untuk mengurangi noise, segmen yang tidak diinginkan, tekstur, nonmaximum suppression, dan hysteresis thresholding untuk menemukan tepi (Young, I. T. 1996).

Pendekatan second-order derivative mendefinisikan piksel tepi berdasarkan perubahan kecerahan atau persimpangan nol (zero crossing) pada bidang gambar (Young, I. T. 1996, Anonymous. 2011). SDGD adalah operator nonlinear yang dapat dinyatakan dalam turunan pertama dan kedua. Selain 
mirip dengan Canny, SDGD juga dikombinasikan dengan low pass filter Gaussian untuk tujuan smoothing (Verbeek, P. W. 1994). Selain itu, operator Laplace digunakan untuk menyederhanakan operasi SDGD (Hagara, M. \& Moravcik, J. 2002).

Operator Laplacian didefinisikan pada Persamaan (1)

$$
\nabla^{2}=\frac{\partial^{2} a}{\partial x^{2}}+\frac{\partial^{2} a}{\partial y^{2}}=\left(h_{2 x} \otimes a\right)+\left(h_{2 x} \otimes a\right)
$$

dimana $h_{2 x}$ dan $h_{2 y}$ adalah filter turunan kedua (second derivative) dan $a$ adalah citra.

Cara mendasar dalam filter turunan kedua diberikan Persamaan (2).

$$
\begin{aligned}
& {\left[h_{2 x}\right]=\left[h_{2 y}\right]=\left[\begin{array}{lll}
1 & -2 & 1
\end{array}\right],} \\
& {\left[h_{2}\right]=\left[\begin{array}{ccc}
0 & 1 & 0 \\
1 & -4 & 1 \\
0 & 1 & 0
\end{array}\right]}
\end{aligned}
$$
Gaussian

Mengaitkan Persamaan (1) dengan hasil filter

$$
b=g_{\sigma} \otimes\left(h_{2} \otimes a\right)=\left(g_{\sigma} \otimes h_{2}\right) \otimes a
$$

dimana $b$ adalah hasil dari operasi Gaussian Filter, $g_{\sigma}$ adalah Gaussian low pass filter dan $h_{2}$ hasil dari laplacian.

Lima derivatif parsial yang digunakan dalam filter SDGD adalah sebagai berikut:

$$
\begin{aligned}
& A_{x x}=\frac{\partial^{2} a}{\partial x^{2}}, \quad A_{x y}=\frac{\partial^{2} a}{\partial x \partial y}, \quad A_{x}=\frac{\partial a}{\partial x}, \\
& A_{y y}=\frac{\partial^{2} a}{\partial y^{2}}, \quad A_{y}=\frac{\partial a}{\partial y} .
\end{aligned}
$$

Oleh karena itu,

$$
S D G D=\frac{A_{x x} A_{x}^{2}+2 A_{x y} A_{x} A_{y}+A_{y y} A_{y}^{2}}{A_{x}^{2}+A_{y}^{2}}
$$

Penjelasan detail tentang SDGD dapat ditemukan di (. 2011, Verbeek, P. W. 1994, El-Glaly, Y. N. 2007).

Berdasarkan kajian yang dilakukan oleh Persoon dkk (2003), filter SDGD memberikan hasil lokalisasi permukaan yang lebih baik, terutama di daerah yang sangat melengkung, dibandingkan dengan teknik deteksi tepi Canny. Dengan demikian, filter tersebut diadopsi dalam dalam penelitian ini. Selain itu, Persoon dkk (2003) menunjukkan bahwa SDGD menjamin minimal detail smoothing yang menyebabkan visualisasi yang lebih baik dari polip di computed tomography (CT) scan data. Selanjutnya, kajian yang dilakukan oleh Nader El-Glaly (2007) menggunakan filter SGDG dalam mengembangkan parsial-diferensial pada algoritma digital inpainting untuk mencari data yang hilang dalam gambar digital.

\subsection{Algoritma Vehicle Analysis}

Pada umumnya, kamera lalu lintas diletakkan pada tempat tertentu, karenanya background-nya diam. Oleh karena itu, metode backgroud subtraction (Thou-Ho dkk. 2007) sangat cocok untuk mendeteksi kendaraan yang bergerak melalui perbedaan yang dihasilkan untuk setiap deteksi perubahan gambar. Fungsi deteksi ditunjukkan sebagai berikut:

$$
D_{i}(x, y)=C_{i}(x, y)-B_{i}(x, y)
$$

dimana $D_{i}(x, y)$ adalah hasil difference image, $C_{i}(x, y)$ adalah current image pada Gambar 1(a) dan $B_{i}(x, y)$ adalah background image pada Gambar 1(b).

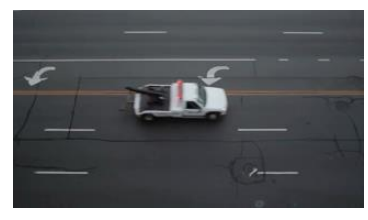

(a)

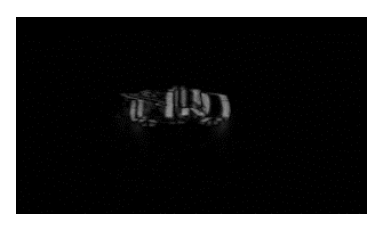

(c)

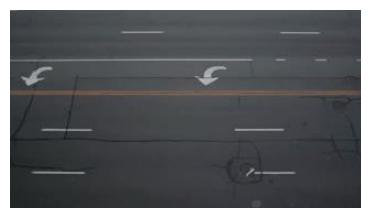

(b)

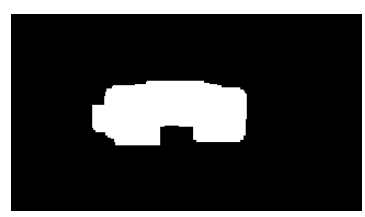

(d)
Gambar 1. Hasil dari Vehicle Segmentation

Hasil dari difference image pada Gambar 1(c) akan diubah menjadi citra biner dengan persamaan berikut:

$$
R_{i}(x, y)=\left\{\begin{array}{l}
0, i f\left|D_{i}(x, y)\right|<T \\
255, \text { otherwise }
\end{array}\right.
$$

dimana $R_{i}(x, y)$ adalah hasil citra biner dan $T$ adalah nilai threshold yang nantinya ditetapkan dari hasil beberapa kali percobaan. Dan pada Gambar 1(d) merupakan hasil SDGD kemudian dilakukan operasi morfologi dengan menerapkan teknik erosi dan dilasi. Detail operasi algoritma Segmentasi Kendaraan dengan Improve BA dapat dilihat pada Gambar 2.

Pada Gambar 2 dijelaskan cara kerja algoritma tersebut adalah serangkaian masukkan objek akan disegmentasi, objek tersebut akan mengalami update background secara terus - menerus sampai seluruh rangkaian masukkan objek tersegmentasi seluruhnya agar membentuk reliable background dan setelah itu dilakukan filter SDGD. Kemudian melakukan blob analysis yaitu ekstraksi fitur seperti perhitungan dispersedness, aspect ratio, dan area ratio pada objek bergerak. Setelah itu dilakukan tracking dan segmentasi akhir. 


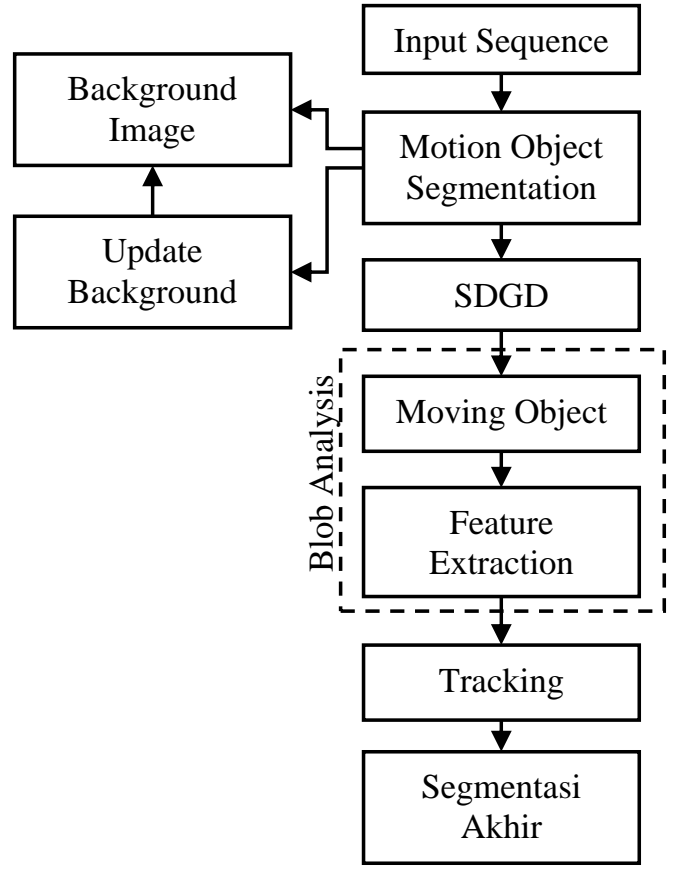

Gambar 2. Algoritma Segmentasi Kendaraan dengan Improve $B A$

\subsection{Ekstraksi Fitur untuk Tracking}

Pada Gambar 2 dibagian blob analysis, ada banyak fitur yang dari objek yang menjadi target bergerak (moving target) seperti tekstur, warna, bentuk, dll. Fitur-fitur ini secara garis besar dapat diklasifikasikan menjadi dua bagian: fitur spasial dan fitur temporal. Fitur spasial digunakan untuk membedakan objek yang berbeda pada waktu yang sama, dan fitur temporal digunakan untuk mengenali objek yang sama pada waktu yang berbeda. Untuk mengenali objek yang berbeda, maka perlu untuk mendapatkan fitur tertentu yang bermakna dan bersifat diskriminatif.

Ketika kendaraan bergerak, fitur yang diekstrak adalah perimeter dan area, yang kemungkinan dapat berubah pada waktu ekstraksi yang berbeda. Untuk mengatasi masalah fitur yang nilainya sering berubah diambil dari objek yang bergerak menggunakan bounding-box (Lin, B. \& Zhou, H. 2002). Oleh karena itu fitur lainnya seperti dispersedness, aspect ratio, dan area ratio juga diukur untuk menyediakan fitur yang stabil pada objek yang bergerak, seperti dijelaskan dalam Persamaan (8), (9), dan (10).

$$
\begin{aligned}
& \text { Dispersedness }=\frac{\text { Perimeter }^{2}}{\text { Area }} \\
& \text { AspectRatio }=\frac{\text { Height }}{\text { Width }} \\
& \text { AreaRatio }=\frac{\text { Area }}{\text { ROI }}
\end{aligned}
$$

Dalam persamaan di atas, Perimeter berarti batas objek bergerak dan Area menunjukkan wilayahnya, tetapi Height, Width dan ROI berarti ketinggian, lebar dan luas (yaitu, Height*Width) dari bounding-box masing - masing. Kemudian menghitung centroid dari masing - masing objek sesuai dengan Persamaan (11).

$$
x_{0}=\frac{\sum_{(x, y) \in R} \sum_{(x, y) \in R} x}{\sum_{(x, y)} 1}, y_{0}=\frac{\sum_{(x, y) \in R} \sum y}{\sum_{(x, y) \in R} 1}
$$

Pada Gambar 3, masing-masing objek ditentukan titik $\left(x_{0}, y_{0}\right)$ yang merupakan centroid objek dan $R$ adalah himpunan pixel objek.

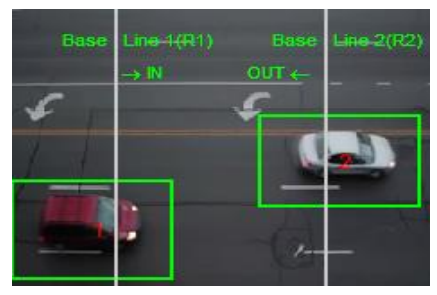

Gambar 3. Hasil Segmentasi Kendaraan

\section{HASIL PENGUJIAN DAN ANALISIS}

Data yang digunakan untuk pengujian berupa file video (.avi) yang diunduh dari internet dengan frame rate 24 fps dan ukuran video 1280x720 piksel. Data video kemudian diekstraksi menjadi gambar (.png) dan diperkecil menjadi 320x280 piksel. Spesifikasi komputer yang digunakan dari perangkat keras yakni prosesor Intel ${ }^{\circledR}$ Core $^{\mathrm{TM}}$ i3-2330M CPU @ 2.20GHz, memori $4 \mathrm{~GB}$, dan dari perangkat lunak menggunakan sistem operasi Windows 10 Pro 64 bit serta aplikasi Matlab. Waktu yang digunakan untuk proses pengujian satu data uji (30 frame) adalah 3 detik.

\subsection{Pengujian Threshold}

Pengujian threshold dilakukan dengan tujuan untuk mengetahui nilai threshold terbaik sehingga dapat menyeleksi citra hasil background subtraction dan membentuk gambar biner dengan baik. Pengujian ini dilakukan dengan mengganti nilai threshold dengan 10 nilai parameter threshold.

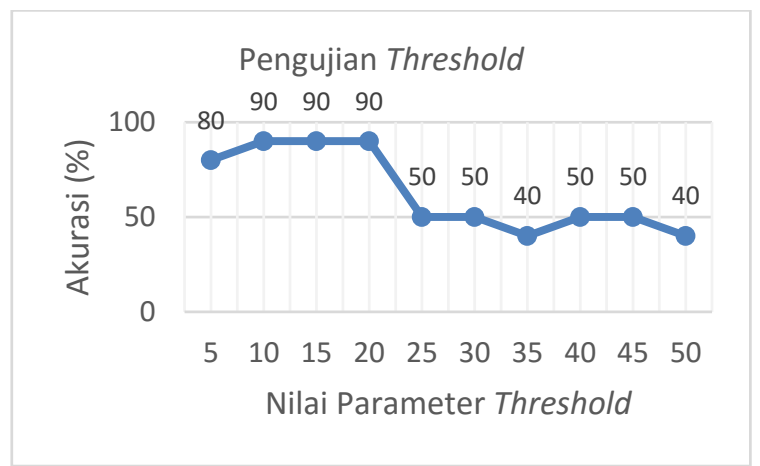

Gambar 4. Analisis Pengujian Threshold

Berdasarkan hasil pengujian threshold dengan 10 data uji, yakni 1 data uji dengan 30 frame dan 10 nilai parameter threshold didapatkan bahwa threshold 10, 15 dan 20 memiliki nilai akurasi 
tertinggi yakni 90\%. Dari hasil ini, dapat disimpulkan bahwa threshold 10, 15 dan 20 merupakan threshold terbaik.

Nilai akurasi dari threshold mengalami kenaikan dan penurunan akurasi. Dari Gambar 4 dapat dilihat bahwa nilai parameter threshold yang mendekati threshold 10, 15 dan 20 akurasinya semakin tinggi dan nilai akurasi yang menjauhi threshold 10, 15 dan 20 akurasinya semakin rendah. Hal ini disebabkan karena jika nilai threshold semakin kecil atau semakin besar maka sistem tidak mampu menyeleksi background dengan baik. Jika threshold semakin kecil, maka background dapat terdeteksi sebagai objek. Sedangkan jika threshold semakin besar, blob - blob objek akan menjadi lebih besar, sehingga dapat menyatu dengan blob yang lain.

\subsection{Pengujian Structure Element}

Pengujian structure element dilakukan dengan tujuan untuk mengetahui ukuran structure element terbaik sehingga dapat membentuk blob dengan baik. Pengujian ini dilakukan dengan mengganti nilai structure element dengan 10 ukuran structure element pada Tabel 1.

Tabel 1. Ukuran Structure Element

\begin{tabular}{ccc}
\hline \multirow{2}{*}{ SE } & \multicolumn{2}{c}{ Ukuran } \\
\cline { 2 - 3 } & Erosi & Dilasi \\
\hline $\mathrm{a}$ & $5 \times 1$ & $10 \times 20$ \\
$\mathrm{~b}$ & $10 \times 1$ & $10 \times 20$ \\
$\mathrm{c}$ & $15 \times 1$ & $10 \times 20$ \\
$\mathrm{~d}$ & $5 \times 1$ & $20 \times 40$ \\
$\mathrm{e}$ & $10 \times 1$ & $20 \times 40$ \\
$\mathrm{f}$ & $15 \times 1$ & $20 \times 40$ \\
$\mathrm{~g}$ & $5 \times 2$ & $15 \times 25$ \\
$\mathrm{~h}$ & $10 \times 2$ & $15 \times 25$ \\
$\mathrm{i}$ & $15 \times 2$ & $15 \times 25$ \\
$\mathrm{j}$ & $5 \times 2$ & $20 \times 40$ \\
\hline
\end{tabular}

\section{Analisis Pengujian Structure Element}

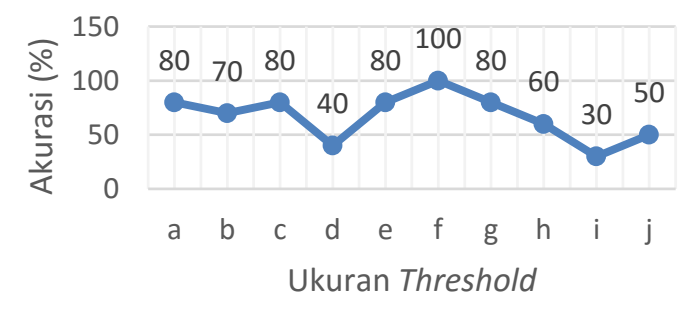

Gambar 5. Analisis Pengujian Structure Element

Berdasarkan hasil pengujian structure element dengan 10 data uji pada Gambar 5, yakni 1 data uji dengan 30 frame dan 10 ukuran structure element (Tabel 1) didapatkan bahwa structure element dengan erosi 15x1 dan dilasi 20x40 memiliki nilai akurasi tertinggi yakni $100 \%$. Dari hasil ini, dapat disimpulkan bahwa ukuran structure element dengan erosi 15x1 dan dilasi 20x40 merupakan ukuran structure element terbaik.

Ukuran structure element yang tepat akan menghasilkan segmentasi blob yang baik. Jika ukuran erosi besar dan tidak diimbangi dengan dilasi yang tepat, maka blob akan terlihat lebih kecil dari ukuran sebenarnya atau dapat menyebabkan sebuah blob akan terpecah menjadi beberapa blob. Tetapi jika ukuran erosi terlalu kecil juga tidak mampu menghilangkan noise yang tidak diperlukan. Sebaliknya jika ukuran dilasi terlalu besar, maka akan menyebabkan ukuran blob lebih besar dari pada objek yang sebenarnya dan dapat menyebabkan beberapa $b l o b$ menyatu menjadi satu blob.

\section{KESIMPULAN DAN SARAN}

\subsection{Kesimpulan}

1. Implementasi Blob Analysis dan SDGD dapat digunakan untuk segmentasi kendaraan pada video lalu lintas.

2. Hasil ekstraksi fitur bergantung pada blob yang dihasilkan sehingga ukuran threshold dan structure element harus tepat untuk menghasilkan blob yang baik. Threshold terbaik adalah threshold 10, 15, dan 20 dengan akurasi 90\%, sedangkan untuk ukuran structure element terbaik adalah erosi $15 \times 1$ dan dilasi 20x40 dengan akurasi $100 \%$.

\subsection{Saran}

1. Diharapkan pada penelitian berikutnya dapat menggunakan data video yang lebih banyak dan dapat mewakili sebagian besar dari variasi jalan dan kendaraan serta dapat ditambahkan juga data dalam bentuk video yang memiliki kualitas resolusi yang tinggi untuk menunjang kelengkapan data sekaligus dapat juga digunakan analisis dalam bentuk data video pada sembarang posisi dengan harapan hal ini akan mampu mengoptimalkan hasil dari nilai akurasi yang didapatkan.

\section{DAFTAR PUSTAKA}

ANONYMOUS. 2011. Image processing fundamentals: derivative-based operation. http://www.mif.vu.lt/atpazinimas/dip/FIP/fi p-Derivati.html.

EL-GLALY, Y. N. 2007. Development of PDEBased Digital Inpainting Algorithm Applied to Missing Data in Digital Images [M.S. thesis]. Ain Shams University.

HAGARA, M \& MORAVCIK, J. 2002. PLUS operator for edge detection in digital images. in Proceedings of the International Conference of Radioelektonika. 467-470. 
LIN BO, ZHOU HEQIN. 2003. Using object classification to improve urban traffic monitoring system. IEEE, International Conference on Neural Networks and Signal Processing, Vol. 2. 1155-1159.

NARENDRA, V. G. \& HAREESH, K. S. 2009. Study and comparison of various image edge detection techniques. International Journal of Image Processing, vol. 4, no. 2, article 83.

PERSOON, M. P., SERLIE, I. W. O., POST, F. H., TRUYEN, R., \& VOS, F. M. 2003. Visualization of noisy and biased volume data using first and second order derivative techniques. in Proceedings of the 14th IEEE Visualization Conference. 379-385.

RAHMAN, F. Y. A. 2013. Enhancement of Background Subtraction Techniques Using a Second Derivative in Gradient Direction Filter. Hindawi Publishing Corporation, Journal of Electrical and Computer Engineering.

THOU-HO, YU-FENG, L, \& TSONG-YI, C. 2007. Intelligent Vehicle Counting Method Based on Blob Analysis in Traffic Surveillance. IEEE, 0-7695-2882-1/07 \$25.00 (C2007.

YOUNG, I. J., GERBRANDS, J.J., \& VAN VLIET, L. J. 2007. Fundamentals of Image Processing. Version 2. 3.

YOUNG, I. T. 1996. Generalized convolutional filtering. in Proceedings of the 19th CERN School of Computing. 51-65.

VERBEEK, P. W. \& VAN VLIET, L. J. 1994. Location error of curved edges in low-pass filtered 2-D and 3-D images. IEEE. Transactions on Pattern Analysis and Machine Intelligence, vol. 16, no. 7. 726733. 